Revista Oficial del Poder Judicial

\title{
La evolución del constitucionalismo peruano y su influencia en la creación de la primera Corte de Justicia de la República
}

The euolution of Peruvian constitutionalism and its influence on the creation of the first Court of Justice of the Republic 0 (웅

LILLY LLAP UNCHÓN

Corte Superior de Justicia de La Libertad

(Trujillo, Perú)

Contacto: lllap@pj.gob.pe

https://orcid.org/0000-0003-2190-0414

\section{RESUMEN}

El artículo estudia la evolución del constitucionalismo en el Perú desde una perspectiva histórica, correlacionando el período desde la etapa previa a la independencia hasta la instalación de la primera Corte de Justicia. El tramo histórico data desde el primer período, denominado prehistoria constitucional de 1810, con el inicio de las Cortes de Cádiz, seguido de la historia constitucional hasta el 30 de abril de 1824. La aproximación, por ser transversal, requiere del 
estudio del liberalismo de inicios del siglo XIX, el constitucionalismo, la teoría de división de poderes y la función jurisdiccional, cuya evolución permitió la instalación de la primera Corte de Justicia. Esta tuvo como fundamento constitucional el artículo 101 de la Constitución de 1823, texto que algunos historiadores consideran que no influyó, lo que este estudio contradice.

Palabras clave: constitucionalismo; liberalismo; Constitución de 1823; división de poderes; Poder Judicial peruano.

\section{ABSTRACT}

The article studies the evolution of constitutionalism in Peru from a historical perspective, linking the period from the pre-independence stage to the installation of the first Court of Justice. The historical tract dates from the first period, called constitutional prehistory of 1810, with the beginning of the Cortes of Cadiz, followed by the constitutional history up to April 30, 1824. The approach, being transversal, requires the study of the liberalism of the early nineteenth century, constitutionalism, the theory of division of powers, and the jurisdictional function, whose evolution allowed the installation of the first Court of Justice. This had as its constitutional basis article 101 of the Constitution of 1823, a text that some historians consider that it did not have any influence, which this study contradicts.

Key words: constitutionalism; liberalism; Constitution of 1823; division of powers; Peruvian Judiciary.

Recibido: 16/05/2021 Aceptado: 01/09/2021 
Hay que recuperar, mantener y transmitir la memoria histórica, porque se empieza por el olvido y se termina en la indiferencia.

José SARAMAgo

\section{INTRODUCCIÓN}

La idea de constitucionalismo alude al límite del ejercicio del poder. También se erige como un movimiento ideológico y una teoría o ideología sobre el principio del gobierno que limita y garantiza los derechos en una dimensión estructural de la organización política social de una determinada sociedad. Así, el modelo inglés de monarquía constitucional, el modelo norteamericano y el modelo francés aportaron principalmente la idea de libertad, la separación de poderes y la soberanía que reposa sobre el parlamento:

El constitucionalismo surge cuando un pueblo rompe con la tradición y la concepción providencial del mundo. Esto es, cuando asume la responsabilidad de hacer su propia historia, cuando deja de ser pasivo y se convierte en protagonista, en autor de su vida colectiva (Sáchica, 2002, p. 3).

Se debe especificar el momento histórico y el constitucional a fin de ubicar el contexto de la evolución del constitucionalismo en el Perú y su influencia en la instalación de la primera Corte de Justicia. El período materia de estudio data aproximadamente de una década antes de la fundación de la república y los años próximos hasta 1824, en los que se determina la nacionalidad. Los hechos políticos, económicos y sociales de gran turbulencia por el afán independentista de dicho período definen la etapa histórica. Sin embargo, los textos jurídicos constitucionales se muestran de avanzada respecto del devenir histórico.

Esta investigación estudia el impacto de las ideas de los diversos modelos constitucionales forjados desde los inicios del siglo XIX 
en la formación de la república peruana, la división de poderes y la consecuente creación de la primera corte de justicia. El constitucionalismo peruano tuvo una fuerte influencia externa desarrollada en Occidente, que también influyó en el desarrollo del constitucionalismo en España: «el constitucionalismo como doctrina ciertamente no ha nacido de repente, como si fuera un relámpago, sino que hunde sus raíces en la historia de la constitución inglesa, idealizada en Francia en el Setecientos, por ejemplo por Montesquieu y De Lolme» (Zagrebelsky, 2013, p. 20).

En la época de la fundación de la república, desde antes de la independencia formal del Perú en 1821, José de San Martín expidió documentos de índole constitucional, como el Reglamento Provisional, el 12 de febrero de 1821, y el Estatuto Provisional, el 8 de octubre de 1821. Posteriormente, se instaló el Primer Congreso Constituyente que dictó las Bases de la Constitución Política de la República Peruana de 1822, que sirvieron asimismo para la Constitución Política de 1823. Según Domingo García Belaúnde (1990), este es el «documento fundacional del nuevo estado constitucional peruano» (p. 60), que considera por primera vez, de acuerdo con el pensamiento liberal predominante, los principios que rigieron la organización del Estado en tres poderes, entre ellos el judicial, así como el reconocimiento de los derechos individuales, previamente a la Constitución de 1823. Algunos autores consideran que, en sentido estricto, no tuvo ninguna influencia por haber sido mortinata al no compatibilizar con la dictadura instaurada por el Congreso a favor de Simón Bolívar, sobre lo cual disiento. Por otro lado, el historiador constitucional citado considera como parte de la prehistoria constitucional peruana a la Constitución de 1812 dictada por las Cortes de Cádiz, jurada en el Perú virreinal y antecedente para la historia constitucional descrita. 


\section{PREHISTORIA DEL CONSTITUCIONALISMO PERUANO}

En otro de sus ensayos sobre la periodificación de la historia constitucional peruana, Domingo García Belaúnde (1997) trata los períodos de la vida política y social, y no solo el marco normativo. Así, diseña dos etapas: la prehistórica o dependiente, desde 1780 hasta 1820, y la histórica, a partir de 1821. Además, establece que la primera etapa empieza en 1780 con el período de convulsiones en el sector doctrinario y guerrero en pos de la independencia, el autogobierno y la disociación de la metrópoli. Del mismo modo, destaca la revolución de Túpac Amaru II y, en el plano ideológico, en 1792, a Juan Pablo Vizcardo y Guzmán por su Carta a los españoles americanos, que genera la idea de independencia que se replica en publicaciones y conatos de rebelión. Entre los sucesos importantes que menciona se encuentran la Carta de Cádiz de 1812, que no solo ejerció influencia en el desarrollo político, social y cultural, sino que obtuvo enormes contribuciones de delegados americanos y culminó en 1820 con la llegada de la corriente libertadora de José de San Martín y, posteriormente, con las conversaciones entre el Libertador y el virrey La Serna, que no arribaron a alguna solución (García Belaúnde, 1997, p. 234).

\subsection{Las Cortes de Cádiz}

\subsubsection{El contexto español}

Dentro del contexto español, la Corona se encontraba en crisis por la disminución de su autoridad y la invasión de Francia. Así, las cortes se reunieron con la finalidad de intentar una maniobra política ante la decisión de la población de optar por las juntas locales y regionales. Se produjo el motín de Aranjuez en el cual el pueblo se rebeló contra la Corona y se organizó en juntas. En 1808, se produjo la invasión francesa, el rey Carlos IV abdicó en favor de su hijo Fernando VII, quien fue recluido en prisión y, nuevamente, abdicó el trono en favor de Carlos IV, que cedió la corona a José 
Bonaparte, proclamado rey de España. El pueblo español independentista se levantó en armas y derrotó a los franceses. Sin embargo, Napoleón Bonaparte atacó nuevamente e ingresó a Madrid y dictó los decretos que abolían la Inquisición y disminuían el poder de la Iglesia, acercándose así al pensamiento liberal español.

Se instalaron varias juntas, las principales fueron las de Aranjuez, Valencia y Granada, así como juntas provinciales, compuestas por la milicia, el clero, los funcionarios y los aristócratas. Existía también una Junta Central con poderes ejecutivos y legislativos, en cuyo seno había liberales y absolutistas que debatían acerca de la solución política convocando a las Cortes. Además, en enero de 1809, siempre en su afán independentista del yugo francés, acordaron que se eligieran también vocales en América para su composición. En 1810, el 1 de enero, la Junta Central convocó a las Cortes en las que los liberales querían limitar el poder monárquico y obtener mayor participación ciudadana. Asimismo, los absolutistas reconocían a Fernando VII como rey. Al disolverse la Junta Central, asumió funciones el Consejo de Regencia, que convocó a los sectores de la nobleza y eclesiásticos y eligió a los representantes suplentes no hispanos, como los americanos.

\subsubsection{La conuulsión americana}

América se encontraba en constantes cambios, con muchas rebeliones e intentos de libertad protestando por el sistema colonialista y reclamando su liberación del yugo español. El enfrentamiento violento se vio acompañado de reformas en la intelectualidad, que recibió influencia de la Ilustración y la Revolución francesa de 1790, la Independencia de Estados Unidos, sus trece colonias y la Declaración de Filadelfia de 1776. Esto se reflejó en las publicaciones de El Mercurio Peruano y la Gaceta de Lima. Otras regiones, como Quito y Bogotá, ya habían gritado su independencia. 
En este contexto político e ideológico, en 1810 se convocó a representantes no solo peninsulares, sino también criollos e indios, pero debido a lo dificultoso del viaje intervinieron accesitarios, a quienes denominaron suplentes. Asimismo, «la convocatoria era el anuncio precedente de las independencias, según unos; según otros, era la ruptura con el Antiguo Régimen» (Vilcapoma, 2015, p. 85), dado que existían los absolutistas y reformistas y los liberales. Los primeros defendían la monarquía y los segundos estaban imbuidos del pensamiento político de la Revolución francesa y la Independencia de Estados Unidos. Ya se esbozaban fórmulas constitucionales con filiación doctrinaria, como los realistas, que recusaban las ideas liberales de la Revolución francesa adscribiéndose al constitucionalismo inglés por la organización parlamentaria; los liberales, que defendían la soberanía nacional y la división de poderes con cortes unicamerales; y los diputados americanos, que se inspiraban en una monarquía con visos federales como la de Estados Unidos.

Las Cortes generales correspondían a toda la nación y las Cortes extraordinarias tenían carácter constituyente. El 24 de septiembre de 1810 se reunieron en Cortes extraordinarias, formándose así una comisión que prepararía el proyecto de la futura constitución. En 1811 se abolió el régimen señorial. Participaron trescientos diputados. Hubo treinta y seis peruanos participantes y asistieron solo doce. No existen datos precisos, pero se menciona que fueron quince, entre los que se destaca al peruano Vicente Morales Duárez, quien participó como diputado por Lima y llegó a presidir las Cortes, así como Dionisio Inca Yupanqui.

\subsection{La Constitución de Cádiz o Constitución gaditana}

La España de 1812 resaltó por el modernismo en su vida política, constitución, libertad, soberanía y división de poderes. Estos conceptos influenciaron en los territorios americanos. Fue la primera 
Constitución española, promulgada el 19 de marzo de 1812 y vigente hasta 1814, fecha en la cual Fernando VII la suprimió y disolvió las Cortes. El proceso constituyente no se limitó al trabajo del proyecto y su aprobación, sino que los constitucionalismos francés, británico y norteamericano ya se habían expandido. Los principios que la caracterizaron fueron el poder constituyente de las Cortes, el principio de soberanía nacional, la división de poderes, la organización judicial y el reconocimiento de los derechos individuales. La soberanía nacional que reside en forma originaria y perpetua en la nación les facultaba dictar su constitución y reformarla, sin que se establezca una jurisdicción constitucional.

La división rígida de poderes es el derrotero para asegurar la libertad, ya que reconoce diversas funciones: administrativa, legislativa y jurisdiccional. Le atribuye un poder a cada una de ellas bajo la denominación de cada órgano que ejercía el poder, como las Cortes, el rey y los tribunales, para desligarse de la redacción de la Constitución francesa de 1791. En lo que atañe a la organización judicial, también estuvo influenciada por el constitucionalismo francés al reconocer tribunales penales, civiles y contenciosos, con un Tribunal Supremo de Justicia. La administración de justicia sufrió un cambio esencial: la función jurisdiccional era realizada por jueces y magistrados bajo el principio de independencia, premisa básica del liberalismo, como lo habían pergeñado Montesquieu y Locke. En esa línea, resultaba conforme a la soberanía nacional y la división de poderes que el Estado constitucional había recogido de las ideas de la Constitución francesa.

La denominación de Constitución Política de la Monarquía Española reconocía el ámbito territorial donde se ejercía la soberanía ya transformada. Las Cortes se constituyeron como el órgano supremo con función legislativa. El rey ya no ejercía de forma exclusiva el poder, solo lo hacía en el ámbito ejecutivo. Tenía participación en la función legislativa y la administración de justicia estaba 
a su nombre. Así se hizo efectiva la democracia y la división de poderes. Entonces, la vida política se tornó en la defensa de la libertad, la soberanía de la nación, las ideas de patria y república, los principios de la democracia, el sufragio masculino, la ciudadanía americana y la autonomía de los pueblos indígenas. Estos principios de justicia, libertad, república y democracia fueron adoptados en nuestra primera constitución.

El liberalismo, pensamiento filosófico político en los albores del siglo XIX que caracterizó la Constitución gaditana, ejerció influencia en el liberalismo peruano que cambió las ideas fidelistas a la monarquía por una corriente independentista. Hasta 1820, el pensamiento liberal no aceptaba cambios en el sistema político. Estaba adscrito a la Corona. La influencia de las Cortes de Cádiz y su principal producto, la Constitución de Cádiz, influyeron en el cambio de modelo constitucional como producto del liberalismo español.

\subsection{Liberalismo en el Perú a inicios del siglo XIX}

El liberalismo como corriente política se ha desarrollado en contextos históricos diversos y ha involucrado en sus principios a distintas fórmulas políticas. Esto no fue ajeno al liberalismo en el Perú en la época de la independencia. Así, concurrieron el liberalismo conservador y fidelista, y el independentista radical. Este último se caracterizó por fundarse en la soberanía popular y la asamblea.

En 1820 no se consideraba aún el tipo de estado independiente como fórmula. Los intelectuales de la época se mostraban contrarios a la violencia en sus publicaciones y entendían que un cambio en la educación y la cultura podían ser la corrección al régimen monárquico imperante. No se vislumbraba la separación, aunque ya se producían rebeliones en el virreinato de inicios del siglo XIX. Los fidelistas solo participaban de cambios menores en la forma de administración y la ubicación de los cargos públicos, que no involucraban una modificación del sistema político. Aún lo acontecido 
en las Cortes de Cádiz y la Constitución gaditana no generaba un movimiento radical, dado que la posición americana no había sido aprobada y más bien se había consolidado el centralismo político, limitando la participación de los americanos. Igualmente, los tributos y la participación en la economía tenían el mismo trato desigual. Además, en el orden social no se había descartado la esclavitud ni reconocido los derechos de los indígenas. Sin embargo, se debe precisar que el 29 de diciembre de 1820 se declaró la independencia en la ciudad de Trujillo, que fue proclamada posteriormente por el Protector del Perú, San Martín, como «ciudad benemérita y fidelísima a la patria».

A partir de esta negativa a las demandas se produjo el tránsito de la ideología del liberalismo fidelista que rompió con la idea monárquica y se irguió sobre una constitución en democracia. En 1822 la intelectualidad liberal adoptó un cambio radical a causa de la forma en que se produjo la emancipación y la falta de cumplimiento de las políticas que España prometió para el mejoramiento de los virreinatos americanos. El historiador Marco Jamanca Vega explica cuáles son los modelos constitucionales en el constitucionalismo de inicios del siglo XIX en Perú. Hubo varias ideas de estado influenciadas por los debates iniciales que reproducían las ideas constitucionales de las Cortes de Cádiz, las primeras constituciones francesas, el constitucionalismo inglés y la Convención de Filadelfia. El autor los divide en cuatro modelos: a) el modelo constitucional inglés, basado en su constitución histórica; b) el gobierno con equilibrio de poderes; c) las instituciones aristocráticas; y d) la monarquía con parlamento bicameral (Jamanca, 2007).

Respecto del constitucionalismo inglés, menciona que era ampliamente conocido por los liberales peruanos, pues los comentaristas británicos de esta corriente fueron divulgados. Prueba de ello son los libros traducidos de Blackstone y de Lolme, que formaron parte de la consulta de los diputados del primer Congreso Constituyente. 
Sin embargo, este sistema político que estudiaba, en aquel entonces, la monarquía constitucional, ya había cambiado al de una monarquía parlamentaria. La primera se trataba del reconocimiento de normas jurídicas aprobadas por el parlamento y las del Common Law después de la Revolución de 1688. La segunda trataba de convenciones constitucionales desde 1714, que encargaban la dirección política a un gabinete y un primer ministro que dirigía el partido con mayoría en el parlamento. Este último no fue aceptado en nuestro contexto porque los liberales optaron por el corte liberal con la fundación de un nuevo Estado basado en la soberanía nacional del modelo francés y recogido en las Cortes de Cádiz.

\section{EL PERÍODO HISTÓRICO DEL CONSTITUCIONALISMO PERUANO}

Este período comienza formalmente el 28 de julio de 1821 con la proclamación de la independencia, aunque el territorio peruano no se encontraba aún libre de la ocupación realista. Antes de que se produzca este suceso, San Martín dictó documentos de contenido constitucional con carácter provisional, como el Reglamento Provisional el 12 de febrero de 1821 y, posteriormente, el Estatuto Provisional el 8 de octubre del mismo año. Mediante el primero, se prepararon las bases para constituir un estado unitario con atribuciones y competencias para presidentes de departamentos como una forma de descentralización administrativa. A través del segundo, se regulaba el régimen de estos mientras se establecía la Constitución Política.

\subsection{Reglamento Provisional de San Martín}

Este reglamento fue expedido en Huaura y tenía el carácter provisional de uso interno. Se dictó el 12 de febrero de 1821 sin que se haya declarado la independencia, con la finalidad de realizar la distribución del territorio de la república. Su artículo 1 dividía el 
territorio que se hallaba protegido por el ejército libertador en "cuatro departamentos: Trujillo, que albergaba los antiguos partidos [...] del Cercado de Trujillo, Lambayeque, Piura, Cajamarca, Huamachuco, Pataz y Chachapoyas, [...] el departamento de Tarma [...], el departamento de Huaylas [...] y [...] el departamento denominado de la Costa» (Ramos, 2008, pp. 40-41). También se encargó de la administración de justicia, ya que el artículo 10 del mencionado reglamento establecía una Cámara de Apelaciones en Trujillo con las facultades de un tribunal supremo de justicia, que se componía de un presidente, dos vocales y un fiscal, que obedeció al contexto político al momento de su creación. Fue suprimida por Decreto Protectoral el 4 de agosto de 1821 y reemplazada por la Alta Cámara de Justicia, ubicada en Lima, después de proclamada la independencia el 28 de julio de 1821:

La instalación de la Alta Cámara de Justicia fue, ante todo, un acto simbólico. Lo importante era dar la sensación a los pueblos de que los libertadores pretendían cambiar las cosas. Todavía no se había convocado a elecciones para organizar el Congreso, que representaría el esfuerzo definitivo para conseguir un Estado soberano. Sin embargo, en la ciudad más importante del Perú, la justicia empezaba a desenvolverse con fines republicanos (Eguiguren, 1953b, p. 508).

Lo que pretendía el general San Martín era sistematizar la administración de justicia e impedir la inexistencia de un Poder Judicial en los pueblos libres, ante el cual los ciudadanos pudieran reclamar respecto de abusos de las autoridades. Más todavía si se había proclamado la independencia en la capital de la república y se había centralizado el poder en esa ciudad. La independencia del Perú condujo a la ruptura que desembocó en el surgimiento de un nuevo derecho peruano, a la evolución del constitucionalismo en nuestra patria, que dejó de lado el sistema colonial de la corona española que ejercía la justicia. En consecuencia, se pasó a una etapa 
intermedia denominada independiente, comprendida entre 1821 y octubre de 1822, en la que se dictaron una serie de decretos y reglamentos de carácter provisional hasta el establecimiento de la Constitución del Estado. Con todo ello, se concretó un poder independiente del sistema colonial antes del poder nacional peruano, con cuatro notas que caracterizan el fenómeno de cambio: la continuidad, el retorno, la repetición y la sustitución (Ortiz, 1989, p. 92).

\subsection{Estatuto Provisional de 1821}

Aprobado por San Martín el 8 de octubre de 1821, García Belaúnde (1997) lo cataloga como «un estatuto de los derechos de las personas y de la estructura del poder» (p. 235). Según el autor, enmarcaba la acción del gobierno en tanto el territorio peruano estaba ocupado por los realistas y se instalara el Soberano Congreso:

Debido a que gran parte del territorio peruano se encontraba ocupado por las fuerzas realistas el Protector del Perú expidió el Estatuto. En su preámbulo se señala la justificación de su promulgación: "para el mejor régimen de los departamentos libres, ínterin se establece la Constitución permanente del Estado» (Morales, 1997, p. 332).

A partir de la cita, se observa que la dación de la Constitución del Estado peruano era postergada para un contexto más oportuno, una vez que los patriotas vencieran a la dominación española. Su primer artículo resalta la religión católica como oficial y el castigo severo a quienes ataquen sus principios y dogmas. Respecto del Poder Judicial, establece el Protectorado, crea ministerios, un Consejo de Estado y municipios. Sobre el denominado Poder Judiciario, indica que la administración de justicia se hará por la Alta Cámara de Justicia y juzgados de menor jerarquía. Las atribuciones del máximo tribunal serían las mismas que las que tenían las audiencias y podía conocer causas civiles y criminales, así como de funcionarios públicos en ejercicio de su función. 
Asimismo, prescribió la urgente necesidad de instalar una comisión para el estudio del reglamento de la administración de justicia. Así, la Alta Cámara de Justicia nombró a los vocales que asumirían tan notable práctica para dejarse de usar las normas utilizadas por los oidores en las audiencias, de tal forma que se demostrara la diferencia entre las leyes de la nueva república y las de España, impregnadas del sentido liberal de la nueva institucionalidad.

\subsection{Bases de La Constitución Política de la República Peruana}

El primer Congreso Constituyente se instaló el 20 de septiembre de 1822. Ante este, San Martín formuló su dimisión el mismo día y asumió en forma provisional el Poder Ejecutivo con la formación de una Junta Gubernativa. El 16 de diciembre de 1822 se dictaron las Bases de la Constitución Política de la República Peruana (Congreso de la República, 1822) por la Suprema Junta Gubernativa, constituida por el mariscal José de La Mar, Manuel Salazar y Baquíjano y Felipe Antonio Alvarado, miembros comisionados por el Soberano Congreso Constituyente, quienes prestaron juramento el 19 de diciembre del mismo año. Fue

el documento fundacional del nuevo estado constitucional peruano, pues aquí se sentaron, por vez primera, los principios relacionados con la organización de los poderes del Estado y la defensa de los derechos individuales, acorde con la filosofía liberal e iluminista predominante de entonces (García Belaúnde, 1990, p. 60).

El primer documento constitucional emitido por el Congreso Constituyente proclamó la república descartando la monarquía sanmartiniana. En su artículo primero señala que la nación peruana está compuesta por todas las provincias peruanas; en el artículo segundo, que la nación es soberana e independiente de la monarquía española y se denomina República peruana; en el artículo noveno, que se protege la libertad individual, la igualdad ante la 
ley y la libertad de imprenta; y en el artículo décimo destaca que el principio necesario para la conservación de la libertad es la división de las funciones del poder en tres, independientes unas de otras, lo cual resalta su liberalismo. El artículo 17 refiere que el Poder Judiciario es independiente y que sus jueces son inamovibles. Dicha inamovilidad dependerá del cargo de los jueces y la justicia penal por jurados, lo que visualiza una carrera judicial.

\subsection{Constitución Política de La República Peruana de 1823}

El 14 de mayo de 1823 el Congreso peruano, mediante decreto, solicitó a Bolívar que acuda al Perú para dirigir la guerra contra los realistas, y este se embarcó en el bergantín Chimborazo luego de recibir el permiso del Congreso colombiano. Fue recibido el 1 de septiembre, se le informó oficialmente sobre el conflicto con Riva Agüero por acusaciones de tratativas con los españoles, y envió fuerzas militares para su captura.

La primera constitución política se promulgó el 12 de noviembre de 1823 (Congreso de la República, 1823) por el primer Congreso Constituyente, que dividió el poder del Estado en tres funciones: legislativa, ejecutiva y judicial. Sin embargo, debilitó al Poder Ejecutivo al instalar la Junta Gubernativa, que dependía de aquel, pues las pugnas por la independencia continuaban. El Libertador Bolívar fue invitado al Perú por el Congreso, fue investido de poderes amplios y asumió la dictadura. La constitución recientemente promulgada fue suspendida en todo lo que fuese incompatible con los poderes que se le habían asignado. Esta constitución, que exaltó el liberalismo, es considerada por algunos autores como mortinata y sin influencia. Sin embargo, solo quedaba sin efecto en lo que fuera incompatible, y el Libertador dictó decretos invocando la carta suprema, como el del 8 de abril de 1824, de consolidación de la propiedad agrícola, en cuyo artículo 4 se establece que en la constitución radica el progreso de la Hacienda, fomentando los 
ramos productivos y disminuyendo las imposiciones a las personas. Asimismo, en el decreto de fundación de la Universidad Nacional de Trujillo, que se dictó el 10 de mayo de 1824, según el artículo 104 de la Constitución política, reza su primer considerando. Dentro de esa orientación constitucional, el 24 de marzo dictó la Orden Suprema de libertad de los esclavos de elegir al amo que prefieran, acorde con el artículo 11.

Esta constitución preveía en el artículo 101 la creación de cortes superiores en los departamentos de Lima, Trujillo, Cusco y Arequipa, además de las que conviniese. Su artículo 98 estableció una Suprema Corte de Justicia que funcionaría en la capital de la República, compuesta por un presidente, ocho vocales y dos fiscales, adoptando el sistema de jurados para resolver sobre hechos y a los jueces sobre la pena a aplicarse. Las leyes españolas aún subsistían en cuanto no hubiese contradicción con los principios independentistas, y se suprimió la confiscación de la propiedad y las penas crueles. Respecto del cargo de los jueces no se estableció la forma de nombramiento, pero en caso de cohecho, prevaricato o procedimiento ilegal que fuera contra la libertad individual, procedía la acción popular.

En la etapa de 1822 a 1823 se llevaron a cabo las campañas de intermedios, enfrentamientos entre realistas y patriotas, lo que dio lugar al motín de Balconcillo en el que el Ejército instaló como primer presidente al militar José de la Riva Agüero. Entonces, el Congreso se vio obligado a suspender la Constitución de 1823, aprobada en este contexto, y nombrar a Simón Bolívar como dictador para que finalice la independencia. Ello originó que, por decreto dictado por el Congreso Constituyente el 21 de junio de 1823, se trasladase la sede del Congreso y el Gobierno, y los demás tribunales, a Trujillo, autorizando ampliamente un poder militar para la seguridad del Congreso y la defensa del departamento. 


\subsection{Decreto de creación de la Corte Superior de Justicia de Trujillo}

En la ciudad de Trujillo, el Congreso decidió invitar al general Simón Bolívar para concluir la guerra de la independencia que se venía librando. El entonces departamento de Trujillo proveyó de recursos al ejército libertador entregando desde dinero y joyas hasta lonas, zapatos, monturas, riendas y herraduras. Con un gran porcentaje del territorio nacional todavía ocupado por los realistas, Bolívar decidió establecer su cuartel en Trujillo (Castañeda, 2009, p. 16).

El 20 de diciembre de 1823, Simón Bolívar llegó a Trujillo y fue recibido con las solemnidades que el 14 de mayo del mismo año el Congreso emitiera en decreto para que dirigiera la guerra contra los realistas. El 10 de febrero de 1824 el Congreso lo nombró dictador como solución a la crisis política de aquella etapa y, con dicha atribución, nombró ministro general a José Sánchez Carrión, con la consiguiente supresión de los otros tres ministerios: «El Libertador era el alma que animó las jornadas, pero Sánchez Carrión fue espíritu y pensamiento, el hombre que no pierde detalle para lograr que el ejército obtenga la libertad del Perú, que él representaba entonces como Ministro General» (Eguiguren, 1953a, p. 456).

Explica el doctor en Historia José Francisco Gálvez que, efectivamente, el Congreso Constituyente concedió el poder al general Simón Bolívar, quien ejerció autoridad política y militar para la salvación de la república, quedando sin cumplimiento los artículos de la Constitución Política, las leyes y los decretos que fuesen incompatibles. Incluso, el Congreso quedó en receso, aunque el Libertador podía reunirlo en caso extraordinario. Las entidades públicas se instalaron en Trujillo, denominándola entonces como ciudad Bolívar. Así, se simplificó la organización estatal con un solo ministerio, y se nombró al Solitario de Sayán durante este contexto de inestabilidad política y militar. Por otro lado, la legislación siguió 
expidiéndose y tenía vigencia en los territorios libres, así como este órgano jurisdiccional cuyo funcionamiento fue paralelo al que se había establecido en la ocupada ciudad de Lima (Gálvez, 2006, p. 133).

El autor Luis Alva Castro (2004) relata que en esta etapa nuevamente Lima fue ocupada por las fuerzas realistas y que el Libertador instaló en Trujillo, el 8 de marzo de 1824, la sede de su gobierno. Este explicó en su Proclama 10, del 11 de marzo, que su condición de dictador no se debía a un deseo personal sino a la coyuntura, y que por ser de carácter circunstancial, tan pronto se derrote a los realistas, el gobierno sería constitucional por las leyes expedidas y por los propios magistrados (pp. 42, 108).

Por decreto dictado por Simón Bolívar, encargado del poder dictatorial del Perú, en su cuartel general de Trujillo, el 26 de marzo de 1824 se estableció la Corte Superior de Justicia del departamento de Trujillo, cuyo artículo 1 se dictó al amparo del artículo 101 de la Constitución Política de la República, promulgada por el primer Congreso Constituyente, que consideraba cortes para Lima, Trujillo, Cusco, Arequipa y los demás departamentos que convengan. En esa misma fecha, dictó el decreto de medidas de gobierno de emergencia y nombró a Trujillo como capital provisional del Perú mientras se liberaba Lima.

El decreto que creó la primera Corte Superior de Justicia establece que la competencia de esta fuese extensiva a todos los departamentos libres, mientras se lograba la libertad de Lima. Estaba compuesta por un presidente, dos vocales y un fiscal. Su primer presidente fue el doctor don Manuel Lorenzo Vidaurre, que posteriormente presidió la Corte Suprema; los vocales, los doctores don Gregorio Luna Villanueva y don Francisco Javier Mariátegui; y el fiscal, el doctor don Gerónimo Agüero. Tenía atribuciones temporales de Corte Suprema. En su artículo 7 se dispuso que para conocer en tercera instancia se debía agregar al presidente y los vocales, 
dos abogados en calidad de conjueces. Con respecto a su organización interna, dispuso que se dicten decretos particulares, ya que no se había creado la Corte Suprema y la Alta Cámara de Justicia no estaba operativa.

Las competencias de las causas fueron referidas a negocios contenciosos entre las partes y dictaminaban que los procesos judiciales se libraran con arreglo a la constitución y las leyes. Seguidamente, para su funcionamiento, se estableció un Tribunal de Seguridad Pública, por decreto del 3 de abril de 1824, para conocer los delitos de sedición, traición e infidencia. Este actuaba en forma sumaria, imponiendo penas. Estaba compuesto por un presidente, dos vocales y un fiscal, los mismos de la Corte Superior de Justicia.

\subsection{Instalación de La primera Corte de Justicia de La Repúbica}

Posteriormente a su creación, la Corte Superior de Justicia del Departamento de Trujillo fue instalada el 30 de abril del mismo año, según el Acta de Instalación (Corte Superior de Justicia del Norte, 1824), que se encuentra en la Sala de Exhibición Histórica de la actual Corte Superior de Justicia de La Libertad, como consta en su primer folio:

\section{República Peruana}

Acta de Instalación de la Corte de Justicia del Norte

En nombre de Dios justiciero, dador y protector de la libertad del hombre, en la ciudad de Trujillo del Perú a treinta de abril del año del nacimiento del Señor de mil ochocientos veinte y cuatro, segundo de la república y cuarto de su gloriosa independencia, reunidos en el cabildo eclesiástico y secular, prelados de las religiones, profesores del foro, Colegio y gran concurso de ciudadanos, que asistieron a la instalación de la corte superior de justicia, establecida conforme a la constitución, se presentó a autorizarla el Señor Doctor Don José Sánchez Carrión, Ministro general de estado y en consecuencia de las facultades concedidas por su Excelencia el 
Libertador de Colombia, dictador del Perú; tomando en mano la gazeta número veintiséis de marzo del presente año, procedió a la lectura del decreto de su creación, la que concluida, dispuso que el Señor Doctor Don Manuel Lorenzo de Vidaurre y Encalada, presidente del Tribunal prestase ante él juramento en esta forma «Juráis por Dios y por los Santos evangelios guardar y hacer guardar la constitución política de la república peruana, sancionada por el Congreso Constituyente, y ser fieles al gobierno, que la nación ha depositado en el Libertador Simón Bolívar? Sí juro. Juráis haberos bien y fielmente en el cargo que se os ha confiado? Sí juro. Si así lo hicieres, Dios os premie, y si no os lo demande, y la nación os haga responsable conforme a las leyes». Consecutivamente el expresado Señor Presidente después de haber tomado su asiento en señal de posesión, recibió el mismo juramento a los Señores Vocales, Doctor Don Gregorio Luna, Doctor Don Francisco Xavier Mariátegui y el Señor Fiscal, Doctor Don Gerónimo Agüero, con lo que ocupando sus respectivas sillas, pronunció el referido Señor ministro un discurso propio del caso, a que contestó dicho Señor presidente; y habiéndole acompañado con los demás Señores Vocales hasta el corredor del tribunal, se dio fin a las citadas ceremonias, notándose en los concurrentes un vivo placer, al ver erigido bajo los auspicios del Libertador de Colombia un baluarte del Perú, que asegurará sus propiedades, honor y fama.

[firmas de] José Sánchez Carrión, Manuel de Vidaurre, Gregorio Luna, FJ Mariátegui, Gerónimo Agüero.

La Corte Superior de Justicia de La Libertad fue la primera corte superior de justicia creada e instalada en la República peruana, conforme a la Constitución de 1823, en su artículo 101, en el cual destaca en el Acta de Instalación la presencia del ministro José Sánchez Carrión, quien se apersonó para instalar la Corte Superior de Justicia, establecida conforme a la constitución. De ello se colige que la instalación de este tribunal primero en la república fue consecuencia directa de la evolución del constitucionalismo peruano y de la dación de la Constitución de 1823, la cual sirvió como fundamento para su creación e instalación. La primigenia 
denominación fue «Corte Superior de Justicia del Departamento de Trujillo», y se instaló como Corte de Justicia del Norte. Posteriormente, el 9 de marzo de 1825, mediante ley, el Congreso Constituyente del Perú dispuso que el departamento de Trujillo se denomine La Libertad, y su capital, Ciudad Bolívar. Así, mediante ley del 21 de julio de 1827, se restituyó a la ciudad de Trujillo su antiguo nombre en sustitución de Ciudad Bolívar. De allí que su denominación actual sea la de Corte Superior de Justicia de La Libertad.

En paralelo a la historia de esta primera corte de justicia, en camino a la pacificación de nuestra patria, en agosto de 1824 el ejército patriota batalló en Junín derrotando al general Canterac y en los tres meses siguientes terminó la ocupación realista en Lima. El enfrentamiento final fue el 9 de diciembre de 1824 en la batalla de Ayacucho, se dio la capitulación y el retiro del último virrey del Perú, a lo que sucedió la creación e instalación de la Corte Suprema de Justicia, por Decreto Dictatorial provisorio del 22 de diciembre de 1824, de acuerdo con el artículo 98 de la constitución y con jurisdicción en los departamentos en los que no se habían establecido cortes superiores (Gálvez, 2006, p. 135), la Corte Superior del departamento de Trujillo era la única en funciones. Otras cortes de justicia también fueron creadas por el Libertador Bolívar, bajo el amparo de la constitución vigente, como la Corte Superior de Justicia de Lima el 22 de diciembre de 1824, la Corte Superior de Justicia del Cusco y la Corte Superior de Arequipa, ambas el 1 de febrero de 1825.

Respecto del funcionamiento de la primera corte, obran en el Archivo Departamental de La Libertad en la subserie republicana, desde 1824, causas civiles, causas criminales, causas de aguas, compulsas, causas administrativas, oficios, pedimentos, razones, etc. La Corte de Justicia también se encargó de la organización administrativa, así que según el decreto bolivariano de 24 de mayo de 1824, los intendentes y gobernadores debían continuar en el ejercicio de 
la judicatura mientras no se designaran jueces de derecho, puesto que en el departamento de La Libertad había un solo juez de derecho en la provincia de Piura, por lo que el señor presidente doctor Gregorio Luna hizo la consulta a la Corte Suprema, acción catalogada como de gran resonancia, pues la administración de justicia se encontraba en manos de imperitos. Se abrió un dictamen de la Comisión Legislativa en 1827, que propuso un proyecto que "consideraba importante conservar la división de poderes», lo que no podía conseguirse con el decreto dictatorial, y, ya que no había número suficiente de letrados en derecho en provincias por escasez de recursos en la arcas públicas, se confiaba la justicia a los alcaldes de las capitales, que debían asesorarse con letrados hasta que se nombren jueces de derecho y estarían bajo la inspección de quienes se encontraban en funciones (Eguiguren, 1953a, pp. 585-587).

El clima político era inestable y fue cesada en funciones (Corte Superior de Justicia del Departamento de La Libertad, 1836) el 17 de febrero de 1836, por despojo violento del general Orbegoso, quien expidió el decreto del 23 de diciembre de 1835 en Huancayo. El 9 de octubre de 1838, en virtud del Supremo Decreto del 17 de septiembre de 1838, retomó el ejercicio de sus funciones con arreglo a la Constitución Política y las leyes vigentes. Así consta en el acta respectiva (p. 1), y se procedió a su apertura en la Sala Consistorial, asignada provisionalmente como sede. Además, consta en anotación marginal que, en octubre de 1888, el ministro de justicia, Dr. Adolfo Villagarcía, presentó un proyecto a la Cámara de Senadores solicitando la supresión de esta corte, que fue recibido con animadversión por el departamento y la ciudad de Trujillo. El pueblo se reunió en una votación popular presidida por la municipalidad, refutaron el proyecto y solicitaron la subsistencia de este órgano jurisdiccional. 


\subsubsection{Apuntes sobre la división de poderes y la función jurisdiccional}

En primer lugar, los poderes se dividen en políticos y jurídicos, y en constituyentes y constitucionales. El poder constituyente se sostiene en la soberanía nacional y enmarca soberanía a la asamblea constituyente y su autolimitación. Los poderes constitucionales legislativo, ejecutivo y judicial se encuentran contenidos en la constitución, y su separación no obedece a la funcionalidad o la economía, sino al poder público, para que estén sujetos a la constitución y no unos a otros. Las funciones del Estado se refieren a funciones jurídicas y se correlacionan con los tres poderes constitucionales. Hay una correlación directa entre los poderes y las funciones del Estado, pero no es una coincidencia en su totalidad.

El profesor de la Universidad Santiago de Compostela, José Julio Fernández Rodríguez (2008), al explicar la evolución del Estado, desarrolla el proceso de separación de poderes y menciona al Estado absolutista monárquico; el Estado constitucional limitado que instaura la división de poderes y la garantía de los derechos individuales; el Estado demoliberal, resaltando la representatividad; el Estado totalitario; y el Estado constitucional, cuyos orígenes se remontan al siglo XVII en Inglaterra, la Declaración de los Derechos del Hombre y del Ciudadano y la división de poderes para garantizar esos derechos, que limitaba a la monarquía, lo que fue descrito por Montesquieu en El espíritu de las leyes: para que no se pueda abusar del poder es necesario que el poder frene al poder. En el liberalismo político y económico moderno, se yergue un Estado liberal bajo los principios de organización y distribución de poderes: es la división de los poderes del Estado. Respecto del Estado de derecho, manifiesta que es una categoría que forma parte del Estado constitucional que surge cuando se imponen los principios de legalidad y de primacía de la ley. 
El constitucionalista Gerardo Eto Cruz (2008) explica que el Estado social y democrático de derecho, que forma parte del constitucionalismo contemporáneo y que ha sido desarrollado por la jurisprudencia del Tribunal Constitucional peruano como una alternativa frente al Estado liberal, tiene sus fundamentos propios, pero le impone funciones sociales como por ejemplo que la propiedad privada no solo debe ser inviolable, sino debe ejercerse dentro de los límites de la ley y en armonía con el bien común (pp. 76-77).

En segundo lugar, el principio de separación de poderes es una teoría propia del Estado moderno, desarrollada por los filósofos de la ilustración John Locke, Bolingbroke y Montesquieu con la finalidad de limitar el poder del gobernante, bajo la premisa del desborde del poder que implica un desconocimiento del derecho de los ciudadanos. García Toma (1999) refiere que resulta notorio que la denominación de teoría clásica de la división de poderes no es exacta con su contenido, pues por el contrario consiste en la distribución de facultades o atribuciones entre los distintos órganos jerarquizados del Estado, y manifiesta que no puede existir división de poderes: de lo que se trata es de una «separación de funciones» y correlativamente una separación de competencias y de autoridades (p. 120).

En tercer lugar, la función jurisdiccional es una potestad conferida a los órganos jurisdiccionales para administrar justicia. Los diversos enfoques se comparan con los diversos estadios en su desarrollo, como en el enfoque clásico que reducía al juez en su capacidad interpretativa y creadora. El legislador creaba las normas y los jueces aplicaban. Sin embargo, el devenir histórico ha otorgado a los jueces mayores desafíos, como decidir inaplicar una ley inconstitucional. 


\section{CONCLUSIONES}

1. Las Cortes de Cádiz y la Constitución de Cádiz, de carácter liberal, influyeron notablemente en América y Perú entre 1810 y 1814 por el debate ideológico de diversos modelos constitucionales, con la participación de americanos y peninsulares. Posteriormente, influyó entre 1820 y 1823 en menor magnitud, puesto que los españoles americanos desarrollaron arraigo con la patria que los vio nacer y fue su lugar de su residencia.

2. Los debates entre los absolutistas y los liberales en las Cortes de Cádiz se produjeron respecto de los principios de justicia, libertad, república unitaria, democracia, división de poderes, ciudadanía americana y autonomía de los pueblos indígenas. Estos principios liberales fueron adoptados en nuestra primera constitución, posterior a las pugnas independentistas, pues se presentaron diversas posturas. Se adoptó como modelo la república representativa, el Estado unitario, la democracia liberal, la división de poderes, la independencia del Poder Judicial, el reconocimiento de derechos individuales y la delimitación geográfica.

3. Producto de un devenir histórico, con el aporte de la Revolución francesa y el constitucionalismo norteamericano en el siglo XVIII, la evolución del constitucionalismo peruano instauró el Estado liberal que consagró la división de poderes, modelo constitucional que se asumió a inicios de la república, con lo que se establecieron tres poderes del Estado, no solo para limitar el poder o evitar su concentración, sino para garantizar los derechos de los ciudadanos.

4. En este contexto, bajo la influencia de las Cortes de Cádiz, la Constitución gaditana y el pensamiento propio de los políticos americanos, el constitucionalismo peruano fue evolucionando, viéndose plasmado en diversos instrumentos constitucionales 
expedidos por José de San Martín. Posteriormente, en la Declaración de la Independencia el 28 de julio de 1821, se considera propiamente la historia constitucional peruana.

5. Las Bases de la Constitución Política de la República Peruana y la Constitución de la República Peruana de 1823 fueron los fundamentos sobre los cuales se reconoció el ejercicio del Poder Judiciario en los Tribunales de Justicia y los juzgados de inferior jerarquía. La afirmación de que la primera constitución no tuvo vigencia no resulta acertada por el desarrollo del capítulo VIII, por el Libertador Bolívar, quien expidió el decreto de creación de diversas cortes de justicia sobre la base del artículo 101 y el establecimiento en la propia Constitución de la Corte Suprema, según el artículo 100.

6. La primera Corte Superior de Justicia de la República Peruana fue la Corte Superior de Justicia del departamento de Trujillo, actual Corte Superior de Justicia de La Libertad, que fue establecida por el artículo 101 de la Constitución Política de 1823, conjuntamente con las Cortes de Lima, Cusco y Arequipa. El Libertador Simón Bolívar dictó el decreto de su creación el 26 de marzo de 1824 y se instaló, con la intervención del ministro José Sánchez Carrión el 30 de abril del mismo año. Estos hechos corroboran que la evolución del constitucionalismo peruano, los matices propios de la época y el contexto histórico ejercieron influencia para el establecimiento del Poder Judicial en la República peruana, partiendo de su primera corte de justicia. 


\section{REFERENCIAS}

Alva, L. (2004). Bolivar en La Libertad (2. ${ }^{a}$ ed.). Universidad Andina Simón Bolívar. https://www4.congreso.gob.pe/congresista/2001/ lalva/publicacion/BolivarenLaLibertad1.pdf

Castañeda. J. (2009). El amanecer de la República en La Libertad. Asociación Marsa.

Congreso de la República (1822). Bases de la Constitución Política de la República Peruana. Lima: 16 de diciembre de 1822. https:// www.congreso.gob.pe/Docs/sites/webs/quipu/constitu/1822.htm

Congreso de la República (1823). Constitución Política de la República Peruana. Lima: 12 de noviembre de 1823. https://leyes. congreso.gob.pe/Documentos/constituciones_ordenado/CONS TIT_1823/Cons1823_TEXTO.pdf

Corte Superior de Justicia del Departamento de La Libertad (1836). Libro de Actas de Acuerdos.

Corte Superior de Justicia del Norte (1824). Libro de Actas de Acuerdos.

Eguiguren, L. A. (1953a). Historia de la Corte Suprema. En Corte Suprema de la República, Anales Judiciales de la Corte Suprema de la República. Año Judicial de 1951. Tomo XLVIII (pp. 405-714). Imprenta Torres Aguirre.

Eguiguren, L. A. (1953b). Historia de la Corte Suprema de Justicia de la República. En Corte Suprema de la República, Anales Judiciales de la Corte Suprema de la República. Año Judicial de 1951. Tomo XLVII (pp. 385-530). Imprenta Torres Aguirre.

Eto, G. (2008). El desarrollo del derecho procesal constitucional a partir de la jurisprudencia del Tribunal Constitucional peruano. Centro de Estudios Constitucionales del Tribunal Constitucional del Perú. 
Fernández, J. J. (2008). Los fundamentos del derecho constitucional (Derecho, Estado y Constitución). Centro de Estudios Constitucionales del Tribunal Constitucional del Perú.

Gálvez, J. F. (2006). El establecimiento del Poder Judicial en el Perú: de la Real Audiencia de Lima a la Corte Suprema de la República (1821-1824). Revista Campus, (3), 71-146.

García Belaúnde, D. (1990). El constitucionalismo peruano en la presente centuria. Derecho PUCP, (43-44), 59-101. https://doi. org/10.18800/derechopucp.199001.003

García Belaúnde, D. (1997). Los inicios del constitucionalismo peruano (1821-1842). Pensamiento Constitucional, (4), 233-244. http://revistas.pucp.edu.pe/index.php/pensamientoconstitucional/ article/view/3304

García Toma, V. (1999). Teoría del Estado y derecho constitucional. Fondo de Desarrollo Editorial de la Universidad de Lima.

Jamanca, M. (2007). El liberalismo peruano y el impacto de las ideas y de los modelos constitucionales a inicios del siglo XIX. Historia Constitucional, (8), 273-287. https://www.redalyc.org/ articulo.oa? $\mathrm{id}=259027578012$

Morales, F. (1997). Forma jurídica de estado en el constitucionalismo peruano del siglo XIX. Pensamiento Constitucional, (4), 329-350. http://revistas.pucp.edu.pe/index.php/pensamientoconstitu cional/article/view/3309/3151

Ortiz, R. (1989). Derecho y ruptura. A propósito del proceso emancipador en el Perú del ochocientos. Fondo Editorial de la Pontificia Universidad Católica del Perú.

Ramos, C. (2008). Historia de la Corte Suprema de Justicia del Perú. Fondo Editorial del Poder Judicial. 
Sáchica, L. C. (2002). Constitucionalismo mestizo. Universidad Autónoma de México. http://ru.juridicas.unam.mx:80/xmlui/handle/ $123456789 / 9297$

Vilcapoma, J. C. (2015). Las Cortes de Cádiz, convulsión en América y España y los diputados peruanos. En Vilcapoma, J. C. (comp.), Las Cortes de Cádiz y su impacto en el Perú y América (pp. 75-124). Fondo Editorial Academia de la Magistratura.

Zagrebelsky, G. (2003). Constitucionalismo. Derechos y Libertades, (29), 19-38. 